\title{
Complementary study of brain metabolism by combined positron emission and computed tomography
}

\begin{abstract}
The basis for this review was the results of the latest scientific and technical developments of the world level, devoted to the peculiarities of the metabolism of biologically active substances in the body of people suffering from various diseases. So at the molecular level it is established that the destructive inflammatory diseases of man, regardless of the level of damage and the causes of their occurrence, are accompanied by a systemic deficit of protein building material in the form of essential amino acids, especially methionine. Simultaneously, oncological diseases are characterized by activation of lipid metabolism mainly at the level of membrane phospholipids in intensively growing cancer cells with the formation of a deficiency in the body of their main precursor, choline. Regardless of the state of human health, all the processes of cellular functional adaptation are accompanied by the consumption of energy carbohydrate material in the form of glucose molecules, with the appearance of its deficiency not only in areas of increased functional interest, but also at the level of the whole organism.
\end{abstract}

Keywords: amino acids, methionine, phospholipids, cancer cells, human health
Volume 5 Issue I - 2018

\author{
Vadim B Berdichevskyy, Boris A \\ Berdichevskyy \\ Tyumen State Medical University, Russia
}

Correspondence: Vadim B Berdichevskyy, Tyumen State Medical University, Urology Clinic, Russian Federation State, Tyumen, Russia,Email doktor_bba@mail.ru

Received: December 25, 2017 | Published: January 25, 2018

\section{Mini review}

The study of carbohydrate (energy) metabolism with the isotope F18-FDG glucose is widely used not only in the search for tumor lesions of different localization, including the brain, but also for the detection of functional inconsistency of cortical structures in neurological pathology. Simultaneously, a whole series of original works showed high informativeness of this type of research in revealing increased tropicity to the glucose isotope of sensory and motor cortical areas in the process of providing their physiological functions. Of great interest are the works devoted to the complementary study of affected tissues with various isotopes, which makes it possible to suggest the most informative preparations in clinical practice. ${ }^{1-5}$

At the same time, today it is considered that healthy human tissues do not accumulate a sufficient number of named isotopes and clinically these studies are of little significance, although all metabolic forms are simultaneously realized at the level of other organ formations, especially intensively in the cerebral cortex. The reason for underestimating the potential of positron emission research is, in our opinion, that PET/CT tomograms fix the processes of hypermetabolism of labeled molecules in pathological foci, while the level of comparative increase in isotope utilization in other healthy structures in these patients has not previously been analyzed by anybody, and this is an opportunity to develop new PET/ CT technologies for studying the metabolism of biologically active substances in the body in real time, which can complement the results biochemical and molecular research.

\section{Acknowledgements}

None.

\section{Conflict of interest}

Author declares that there is no conflict of interest.

\section{References}

1. Phelps ME. Positron emission tomography provides molecular imaging of biological processes. Proc Natl Acad Sci USA. 2000;97(16):9226-9233.

2. Rainville P, Bushneil MC, Duncan GH. PET studies of the subjective experience of pain. In: Pain Imaging. Progress in pain research and management. In: KL Casey, MC Bushneil editors. Seattle, USA: IASP Press; 2000. p. 123-156.

3. Berdichevskyy VB, Sufianov AA, Elishev VG. Analysis of the brain positron emission tomography data using $18 \mathrm{~F}-\mathrm{FDH}$ during neurophysiological control lower urinary tract. Experimental and clinical urology. $2013 ; 4: 30-34$.

4. Fowler Clare J, Derek Griffiths, William C de Groat. The neural control of micturition. Nat Rev Neurosci. 2008;9(6):453-466.

5. Griffiths D, Derbyshire S, Stenger A, et al. Brain control of normal and overactive bladder. J Urol. 2005;174(5):1862-1867. 